\title{
Cultural heritage and its environment: an issue of interest for Environmental Science and Pollution Research
}

\author{
Michel Sablier • Philippe Garrigues
}

Received: 28 November 2013 / Accepted: 11 December 2013 / Published online: 28 January 2014

(C) Springer-Verlag Berlin Heidelberg 2014

The study of the effects of atmospheric pollution on architectural and artistic works, especially on those of great historical and cultural importance, has become more widespread in the scientific community in the last few years. Environmental Science and Pollution Research (ESPR), as a medium of published work covering all areas of Environmental Science, has not been exempt from this situation. A brief screening of recent articles published in ESPR confirms the issue of interest for Cultural Heritage in its environment.

The practice of conservation of works of art is more and more concerned by the physicochemical characterization of the materials used to help in the understanding of their past chemical evolution and in foreseeing their possible future chemical evolution. Additional major topics concern the best means of restoring them to their pristine state, as well as preserving their present state.

Monuments with great cultural and artistic interest are often located in areas where anthropic activity is non-negligible. Consequently, air pollution, exhausts from industrial plants, and public transport mainly contribute to the damage of building exteriors. Meanwhile, innermost areas of historical buildings and museums are not exempt from indoor pollution effects. The heating, ventilation, and air-conditioning systems may act as discernable sources of gaseous pollutants and particulate matter. Moreover, due to the growing popularity

Responsible editor: Philippe Garrigues

M. Sablier $(\bowtie)$

Muséum National d'Histoire Naturelle, Centre de Recherche sur la Conservation des Collections CRCC, USR 3224 du CNRS, 36, rue Geoffroy Saint-Hilaire, 75005 Paris, France

e-mail: michel.sablier@mnhn.fr

\section{P. Garrigues}

Institut des Sciences Moléculaires, Université de Bordeaux, CNRS, UMR 5255, 33405 Talence Cedex, France

e-mail: p.garrigues@ism.u-bordeaux1.fr of works of art and monuments, the increasing impact of the flow of visitors to monuments, caves, or museums may be also influential.

The difficulties faced by curators and persons involved in art conservation under polluting conditions are then relevant to techniques able to provide an answer to the large set of questions raised by the natural and non-natural weathering of Cultural Heritage. As a first approach, this observation confirms how the choice of a journal involved in both environmental and pollution research is suited for the publication of articles reporting studies in a domain relevant to Conservation Sciences.

On the basis of a brief overview of articles published in ESPR within the five last years, this editorial proposes to reexamine the problems of pollution in the domain of Cultural Heritage. This outing among the recently published articles in ESPR confirms that atmospheric pollution and air contaminants, airborne microorganisms, and heavy metals are the common denominators for recent investigations dealing with Cultural Heritage published in ESPR.

The reviewed articles were mostly referenced under the principal discipline heading "environmental sciences" and under several sub-discipline headings: "pollution and remediation", "environmental chemistry", "environmental healthpublic health," and "environmental toxicology". Diversity of these sub-headings demonstrates objectively how Cultural Heritage and its surrounding environment inscribe itself in the different scopes of studies of ESPR.

Most of these articles treat the deterioration of monuments, in particular, with the adverse effects of inorganics. Indeed, atmospheric pollution acts as a noticeable accelerating factor in the material deterioration of buildings.

Briefly, gaseous $\mathrm{NOx}, \mathrm{SO}_{2}, \mathrm{O}_{3}, \mathrm{HNO}_{3}$, particulate matter, and acid rainfall are the chemicals or the chemical processes responsible for these adverse effects (Varotsos et al. 2009). The hazardous pollutants with strong oxidizing power $\left(\mathrm{NO}_{2}\right.$, 
$\mathrm{SO}_{2}$, and $\mathrm{O}_{3}$ ) are of concern for their potential to initiate chain reactions, giving rise to acidic substances that can directly act on the various substrates, while volatile organic compounds (VOCs) are monitored for their potential to generate $\mathrm{O}_{3}$ under light-exposition conditions.

An original approach towards establishing the relation between monuments and pollution (Rampazzi et al. 2011) was proposed for the quantitative sampling on the cement mortar surface of a modern sculpture, the Camerlata Fountain in Como, Italy. Based on the consideration that monuments may act as passive samplers, the authors used voltammetry to measure platinum and rhodium concentrations, each of them as tracers of automotive emission, and thereby probe for environmental pollution coming from the vehicular pollution.

Chemical analysis of the stained-glass windows and characterization of the patinas developed at their surface are an unavoidable first step in the definition of the best restoration practices to be followed. For the preservation of stained-glass window in the Pedralbes Monastery, Barcelona, Spain, the combination of X-ray diffraction techniques and Fourier transform infrared spectroscopy techniques has demonstrated its potential for the determination of the degree of weathering via the characterization of their patinas (Aulinas et al. 2009). The preliminary evaluation of the degree of weathering deduced from these analyses was correlated with the composition of the observed patinas, the composition of the original glass, as well as the environmental conditions of the deposition in the city of Barcelona.

However, a clear quantification of the impact of the different extrinsic environmental factors of deterioration is difficult. The study of medieval-like model glasses, exposed to simulated atmospheric conditions, permitted the evaluation of the role of both the composition and the surrounding environment on potash-lime glass weathering (Gentaz et al. 2011). This study also highlighted the differentiation to make between wet and dry deposition conditions in the weathering process.

In concert with restoration campaigns, studies can be initiated for a better understanding of factors affecting the degradation of buildings. The restoration project of historical limestone buildings in Bordeaux (France) using laser cleaning among other cleaning methods gave the opportunity to investigate, in the meantime, the composition of the black crust deposited on the surface of the monuments (Chapoulie et al. 2008). This study gave an insight into how porous carbon microparticles, atmospheric dusts, and aluminosilicate particles can be cemented by gypsum.

Owing to the varying extent of hydration of magnesium sulfate which contributes to the formation of the salt efflorescences, the identification of sulfur sources deserves a particular attention to be able to trace its natural or anthropogenic origin. The isotope ratio measurement of $\delta^{34} \mathrm{~S}$ and $\delta^{18} \mathrm{O}$ values by isotope ratio mass spectrometry (IRMS) has proven to be an efficient way to clarify the origin of salt efflorescence on buildings in the Old Town of Salamanca, Spain (Schleicher et al. 2010). The combination of $\delta^{34} \mathrm{~S}$ and $\delta^{18} \mathrm{O}$ value measurements has clarified the potential contribution of vehicle exhausts and heating fuel combustion during wintertime, while the role of mortars was proposed to explain the span of $\delta^{34} \mathrm{~S}$ value distribution among the examined samples. These results demonstrated the need to investigate the isotopic composition of atmospheric aerosols for a definitive attribution of the main sulfur sources in the processes of salt efflorescences that contribute to the alteration and the deterioration of building materials.

Each of these papers highlighted the primary role played by the environment and pollution in the weathering processes. Nevertheless, due to the multiple factors susceptible to explain the origin of weathering, the scope of investigation must be enlarged, and combined studies are often necessary to explain the origin of degradation mechanisms.

The effect of pollution due to air contaminants as well as soluble salts inside churches and monuments is not easily predicted because these contaminants may behave differently on the different materials: for example, wood and brick react differently than stone and mortar to the damaging action of salts and pollutants (Morabito et al. 2013). Internal or external sources may be deduced from the distribution of elements and pollutants depending on the place of sample collection. However, due to the different behavior of different contaminants on different materials, the effect of pollution inside monuments is not easy to predict. Moreover, synergistic effects are often expected, which call for innovative approaches.

In this context, laser ablation inductively-coupled plasma mass spectrometry associated with traditional micromorphological and microscopy analysis and infrared spectroscopy techniques constitute an original methodological approach for the chemical characterization of black crust deposits on stone monuments (Barca et al. 2010). Demonstration of the reliability of the laser ablation technique confirmed how this technique can help in accurate determination of the concentration of various trace elements in the black crusts, providing information on the state of conservation, the degree of deterioration of stones, and extent of pollution.

Similarly, combined spectrometric analyses for the identification of pollution sources in three different churches belonging to the European built Heritage: the Corner Palace in Venice (Italy), the Cathedral of St. Rombouts in Mechelen (Belgium), and the Church of St. Eustache in Paris (France), have demonstrated how the concentration of heavy metals and the composition of black crusts observed on stone surfaces could be a fingerprint of fuel usage over time (Belfiore et al. 2013). These results corroborated how investigations can reveal in which ways crust formation was greatly influenced by the varying degrees of anthropogenic pollution over time. 
Passive sampling was performed to study the coverage rate of airborne particulate matter in the indoor environment of the National Tile Museum, Lisbon (Portugal), in order to evaluate the effectiveness of adding glass panes in the building to restrain airborne pollution inside the museum (Anaf et al. 2013). These investigations revealed the utility of particulate matter sampling to control risks of blackening, abrasion, catalysis, and biodeterioration favored by particulate matter.

Besides the influence of air pollution, organics and microorganisms are also known for their adverse effects in the preservation of historical works of art. The physical parameters of influence (temperature, relative humidity) in the likely degradation of artworks in confined environments like museums must be controlled, but airborne microorganisms should also be monitored (Lee et al. 2011).

Estimation of the influence of microorganisms under exhibition conditions in caves or grottos focuses mainly on the determination of the ratio of the entry and the dispersion of microorganisms and their nutrients into the interior of the cave. This ratio commonly depends on the exchange rates between the inner atmosphere and exterior through the main entrance, galleries, or other ventilation outlets.

Among cultural properties, caves represent a special case because they usually show a stable and fragile confined environment that makes them very susceptible to disturbances resulting from human activities. As a consequence, caves are directly impacted by tourism. One effect resides in the erosion caused by mechanical removal of sediment particles. Other evident impacts interrupting the fragile geochemical/ environmental balance are the increase of $\mathrm{CO}_{2}$ concentration, the increase of water vapor, and temperature variations. Moreover, these effects may provoke uncontrolled chain reactions at the origin of corrosion, which contribute to rock surface weathering independently from the presence of historical paintings and engravings. The direct impact of visitors, in terms of microbial dispersion, the replacement of the natural microbial communities by alien human-induced microbial populations, or the pool of pathogenic microorganisms thriving inside the caves (Fernandez-Cortes et al. 2011) is less well-known. Application of stable isotope determination experiments $\left(\delta^{13} \mathrm{C}\right)$ in trace gases has demonstrated its usefulness in the characterization of gas exchange processes to explain the origin of dispersion of the microorganisms in the Altamira cave, Spain, where the deterioration of rock art paintings by microbial action has been observed (GarciaAnton et al. 2013).

The maintenance of very stable microclimates due to limited air exchange with the external atmosphere, a prerequisite for a proper state of conservation until now, brings into question the role of tourism in the preservation of World Heritage through the influence of massive visits and the hitherto abundance of available nutrients provided. Two recent studies illustrate this point: investigations on the Emperor Qin's Terra-Cotta Museum in Xi'an, China (Chen et al. 2010) and the show cave of Ardales, Spain (Fernandez-Cortes et al. 2011). In the case of Emperor Qin's Terra-Cotta Museum in Xi'an (Chen et al. 2010), passive sampling during the congested yearly rush of the golden-week visits did not reveal microbial concentration in the outer range of regular indoor guidelines. The study focused rather on the side effect of particle sedimentation on surface of displays with the likely release of enzymes and organic acids. As a result, it was stated that investigation to assess the effects of fungal colonization of works of art with regard to any influence of fungal metabolism products is a necessity to determine the risks associated with the presence of fungi on their surfaces as a result of particle sedimentation. These studies shed light on the inner atmosphere dynamics and contributed to the management and conservation of geological and cultural heritage sites.

Heavy metal poisoning, especially arsenic, is a matter of concern in Cultural Heritage since a large part of museum collections (herbarium, natural history specimens) have been exposed to such metal species mainly for conservation purposes. But the introduction of heavy metals in the environment through the mining and refining of metals is also relevant for environmental studies since the ancient modes of industrial production, agriculture, livestock management, and the activities of everyday life may have increased the exposure of ancient populations towards toxic substances in their environment (Harrison et al. 2010).

In conclusion, the interface between disciplines currently applied in Conservation Sciences and Environmental Sciences is particularly well-suited for what can be defined as a fertile field where methodologies, analytical techniques, and ideas issued from each specific scientific area may be optimized and ultimately applied with inventiveness. Cultural heritage materials due to their diversity are extremely challenging in that regard. There is no doubt that the aforementioned articles published during these five last years in ESPR corroborate it.

The entirety of the works reported in the field of environmental pollution applied to Cultural Heritage clearly shows how, today, chemical research associated with these investigations is a very active and productive field. As previously stated elsewhere (Mazzeo et al. 2011), a new trend in the scientific community involved in conservation consists in focusing its interest into problem-solving approaches that favor studies aimed at providing feasible and durable solutions to specific conservation problems, beside studies focusing on a complete knowledge of the constitution of heritage materials and ancient production techniques.

From the above reviewed articles, won't it be possible to extract guidelines for future works?

Noticeably, the standards for the accepted levels of microorganisms are usually set for the health of visitors to museums 
rather than for the preservation of cultural properties. One must consider that, as the management standards have not been established on the basis of the preservation of cultural properties, it may be necessary to modify these standards for airborne bacteria and fungi for the protection of the cultural properties. This necessitates further investigation.

Notwithstanding that viable airborne organisms are not necessarily air pollutants, they should at least be considered as factors affecting air quality. It is commonly accepted that exposure to large concentrations of airborne microbes is often associated with asthma and rhinitis, hypersensitivity pneumonitis, and the so-called "sick building" syndrome. Examination of the relation between worker exposure to airborne microbes and health effects would be of great concern in a precautionary approach in considering the health of the personnel working daily in the presence of these airborne organisms.

At present, considerable efforts are also under way to develop portable instrumentation for non-invasive analyses to be carried out on-site, where the object is located or exhibited. The act of bringing the laboratory near to the works of art reduces the risk and costs associated with the transportation of precious objects. Equally, it opens the way to the scientific examination of a greater number of works of art. One can expect that the development of new portable instruments (Portable X-ray Fluorescence, unilateral portable NMR) will be at the origin of in situ experimentations in the scope of the journal. As an illustration, a recent study on the gildings of mediaeval wall paintings revealed the potential of spectrofluorimetry for studies which require in situ analysis (Mounier et al. 2011).

Concerning outdoor pollution, a future challenge for the influence of environment on the deterioration of built Cultural Heritage consists in the assessment of combined effects in multi-pollutant situations (for example, the effect of sulfur pollutants in combination with NOx, considering climatic parameters and the concerned materials). Moreover, the use of passive sampling devices that allow the characterization of the unknown deposited mass on control particle collectors besides water-soluble fractions may constitute an open field for further investigation.

All new contributions in the field of Cultural Heritage and its environment in ESPR are thus welcome and will be greatly appreciated.

\section{References}

Anaf W, Horemans B, Madeira TI, Luisa Carvalho M, De Wael K, Van Grieken R (2013) Effects of a constructional intervention on airborne and deposited particulate matter in the Portuguese
National Tile Museum, Lisbon. Environ Sci Pollut Res 20: $1849-1857$

Aulinas M, Garcia-Valles M, Gimeno D, Fernandez-Turiel JL, Ruggieri F, Pugès M (2009) Weathering patinas on the medieval (S. XIV) stained glass windows of the Pedralbes Monastery (Barcelona, Spain). Environ Sci Pollut Res 16:443-452

Barca D, Belfiore C-M, Mirocle Crisci G, La Russa M-F, Pezzino A, Ruffolo SA (2010) Application of laser ablation ICP-MS and traditional techniques to the study of black crusts on building stones: a new methodological approach. Environ Sci Pollut Res 17:14331447

Belfiore CM, Barca D, Bonazza A, Comite V, La Russa MF, Pezzino A, Ruffolo SA, Sabbioni C (2013) Application of spectrometric analysis to the identification of pollution sources causing cultural heritage damage. Environ Sci Pollut Res 20:8848-8859

Chapoulie R, Cazenave S, Duttine M (2008) Laser cleaning of historical limestone buildings in Bordeaux. Appraisal using cathodoluminescence and electron paramagnetic resonance. Environ Sci Pollut Res 15:237243

Chen YP, Cui Y, Dong J-G (2010) Variation of airborne bacteria and fungi at Emperor Qin's Terra-Cotta Museum, Xi'an, China, during the "Oct. 1" gold week period of 2006. Environ Sci Pollut Res 17:478485

Fernandez-Cortes A, Cuezva S, Sanchez-Moral S, Cañaveras JC, Porca E, Jurado V, Martin-Sanchez PM, Saiz-Jimenez C (2011) Detection of human-induced environmental disturbances in a show cave. Environ Sci Pollut Res 18:1037-1045

Garcia-Anton E, Cuezva S, Jurado V, Porca E, Miller AZ, FernandezCortes A, Saiz-Jimenez C, Sanchez-Moral S (2014) Combining stable isotope $(\delta 13 \mathrm{C})$ of trace gases and aerobiological data to monitor the entry and dispersion of microorganisms in caves. Environ Sci Pollut Res 21:473-484

Gentaz L, Lombardo T, Loisel C, Chabas A, Vallotto M (2011) Early stage of weathering of medieval-like potash-lime model glass: evaluation of key factors. Environ Sci Pollut Res 18: 291-300

Harrison AP, Cattani I, Turfa JM (2010) Metallurgy, environmental pollution and the decline of Etruscan civilisation. Environ Sci Pollut Res 17:165-180

Lee CM, Kim YS, Nagajyothi PC, Thammalangsy S, Goung SJN (2011) Cultural heritage: a potential pollution source in museum. Environ Sci Pollut Res 18:743-755

Mazzeo R, Roda A, Prati S (2011) Analytical chemistry for cultural heritage: a key discipline in conservation research. Anal Bioanal Chem 399:2885-2887

Morabito E, Zendri E, Piazza R, Ganzerla R, Montalbani S, Marcoleoni E, Bonetto F, Scandella A, Barbante C, Gambaro A (2013) Deposition in St. Mark's Basilica of Venice. Environ Sci Pollut Res 20:2579-2592

Mounier A, Belin C, Daniel F (2011) Spectrofluorimetric study of the ageing of mixtions used in the gildings of mediaeval wall paintings. Environ Sci Pollut Res 18:772-782

Rampazzi L, Giussani B, Rizzo B, Corti C, Pozzi A, Dossi C (2011) Monuments as sampling surfaces of recent traffic pollution. Environ Sci Pollut Res 18:184-191

Schleicher N, Hernández CR (2010) Source identification of sulphate forming salts on sandstones from monuments in Salamanca, Spain - a stable isotope approach. Environ Sci Pollut Res 17:770 778

Varotsos C, Tzanis C, Cracknell A (2009) The enhanced deterioration of the cultural heritage monuments due to air pollution. Environ Sci Pollut Res 16:590-592 


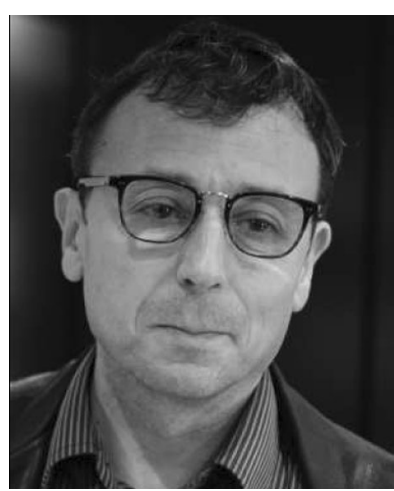

Michel Sablier has graduated in chemistry from the Université Pierre et Marie Curie, Paris. He joined the CNRS in 1994, and actually holds a position as Senior Researcher. His scientific activity has been dedicated to mass spectrometry and its application in various fields: instrumental development, gas-phase studies of ionmolecule and ion-radical reactions, detection of emerging pollutants in the Environment. Beside fundamental chemistry studies, he has always motivated a deep interest for the applications of modern mass spectrometry to the domain of Cultural Heritage. Recently he joined the Centre de Recherche sur la Conservation des Collections at the Muséum National d'Histoire Naturelle, Paris. He is now actively involved in research projects devoted to cellulosic materials for the characterization of chemical markers of origin, of deterioration and contamination in ancient papers using mass spectrometry methods.

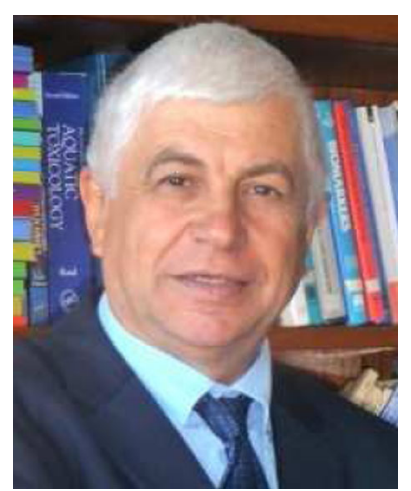

Phillippe Garrigues is a CNRS Research Director and currently the Head of the Institute of Molecular Sciences at the University of Bordeaux. His research interests are the analytical aspects related to the detection of organic pollutants in environmental matrices and the toxicological effects of these compounds. His recent research interests deal with : (1) REACh regulation and how analytical chemistry is developed for its implementation, (2) Life Cycle Assessments of Chemicals. Dr. Garrigues has authored about 180 publications. He is also Editor of the journal ABC (Analytical and Bioanalytical Chemistry) and Editor in Chief of the journal ESPR (Environmental Science and Pollution Research). 